\title{
EXTRATO DE Coffea racemosa COMO ALTERNATIVA NO CONTROLE DO BICHO-MINEIRO DO CAFEEIRO
}

\author{
Coffea racemosa extract as an alternative for the control of coffee leaf miner
}

\author{
Dejane Santos Alves ${ }^{1}$, Denilson Ferreira Oliveira² ${ }^{2}$ Geraldo Andrade Carvalho ${ }^{3}$, Mírian Aparecida Isidro Santos ${ }^{2}$
}

\begin{abstract}
RESUMO
Objetivou-se, com o presente trabalho, verificar o efeito do extrato metanólico de Coffea racemosa Lour., espécie silvestre de cafeeiro portadora de resistência a uma das principais pragas da cultura cafeeira, o bicho-mineiro. Inicialmente, o extrato metanólico das folhas de $C$. racemosa foi pulverizado em mudas de cafeeiro Coffea arabica cv. Catuaí, em casa-de-vegetação, as quais foram expostas a adultos de $L$. coffeella para o teste de oviposição com chance de escolha. Observou-se que as plantas tratadas foram menos preferidas para oviposição. A seguir, realizou-se o teste de efeito ovicida, no qual mudas de C. arabica contendo ovos do bichomineiro foram pulverizadas com o mesmo extrato. Os experimentos foram conduzidos em delineamento inteiramente casualizado com cinco repetições. Verificou-se redução significativa na eclosão de larvas, e segundo análise por microscopia eletrônica de varredura, os ovos não viáveis apresentaram anomalias nas superfícies externas. Entretanto, os adultos provenientes de ovos tratados não foram afetados na percentagem de emergência, razão sexual e oviposição. Os resultados obtidos demonstram que C. racemosa apresenta-se como uma alternativa promissora ao controle do bicho-mineiro, necessitando, no entanto, de novos estudos para isolamento e identificação das substâncias bioativas.
\end{abstract}

Termos para indexação: Leucoptera coffeella, inseticida botânico, café, produtos naturais.

\begin{abstract}
The objective of this study was to evaluate the effect of Coffea racemosa Lour. methanolic extract, a wild coffee specie that presents resistance against the coffee leaf-miner, a major pest of coffee crop. The methanol extract of $C$. racemosa leaves was sprayed on coffee seedlings, Coffea arabica cv. Catuaí, in greenhouse, which were exposed to adults of L. coffeella for oviposition in free choice test. Plants treated were less preferred for oviposition. An ovicidal assay was carried out by spraying the methanol extract on $C$. arabica seedlings containing $L$. coffeela eggs on their leaves. The experiments were conducted in a completely randomized design with five replicates. Larvae hatching out from treated eggs were significantly reduced by the extract and non viable eggs presented some anomalies on their external surfaces according to analyses by scanning electron microscopy. However, the adults derived from treated eggs did not have the percentage of emergence, sex ratio and oviposition affected by the treatment. The results show that C. racemosa presents as a promising alternative to control the coffee leaf-miner, being necessary new studies to isolate and caracterize the bioactive substances against this pest.
\end{abstract}

Index terms: Leucoptera coffeella, botanical insecticide, coffee, natural products.

(Recebido em 8 de outubro de 2009 e aprovado em 11 de agosto de 2010)

\section{INTRODUÇÃO}

O bicho-mineiro Leucoptera coffeella (GuérinMèneville \& Perrottet, 1842) (Lepidoptera: Lyonetiidae) destaca-se como praga-chave da cultura cafeeira. Em decorrência, existe uma grande demanda por novas alternativas para o controle desse inseto, dentre as quais se destaca a possibilidade de se empregarem produtos de origem natural. Nesse sentido, são inúmeros os relatos, em literatura, da aplicação de produtos naturais para o controle de pragas agrícolas (Almeida et al., 2006; Mendonça et al., 2006; Gonçalves-Gervásio \& Vendramim, 2007; Oliveira et al., 2007; Pereira et al., 2008; Santiago et al., 2008; Silva et al., 2008; Lima et al.,2009; Rossi et al., 2010).
Uma possível alternativa para atender à demanda de novas formas de controle para o bicho-mineiro consiste no uso de Coffea racemosa Lour. (Rutaceae), por ser uma espécie silvestre resistente ao bicho-mineiro. Já existem relatos, na literatura, de trabalhos que buscam utilizar C. racemosa como doadora de genes para Coffea arabica $\mathrm{L}$. (Rutaceae). No entanto, por se tratar de uma cultura perene, propagada via sementes, os programas de melhoramento genético do cafeeiro são muito longos e resultados satisfatórios ainda não foram alcançados (Mendes, 2008).

Apesar da escassez de informações a respeito do mecanismo de resistência de C. racemosa a L. coffeella, sabe-se que não há qualquer correlação entre as

1Universidade Federal de Lavras/UFLA - Cx. P. 3037 - 37200-000 - Lavras, MG - dejane_bio@yahoo.com.br

${ }^{2}$ Universidade Federal de Lavras/UFLA - Departamento de Química/DQI - Lavras, MG

${ }^{3}$ Universidade Federal de Lavras/UFLA - Departamento de Entomologia/DEN - Lavras, MG 
características anatômicas foliares e o referido mecanismo (Ramiro et al., 2004). Logo, uma possibilidade para explicar tal resistência seria a produção de substâncias inseticidas pela planta que estariam atuando contra o bicho-mineiro.

Contudo, pouco se sabe sobre quais classes de substâncias estariam atuando de forma isolada ou conjunta na resistência de C. racemosa ao bichomineiro. Já foi investigado, por exemplo, o papel do alcalóide cafeína na resistência de híbridos de $C$. arabica e $C$. racemosa; entretanto, não foi observada correlação entre a redução dos danos foliares e teor de cafeína do tecido (Guerreiro-Filho \& Mazzafera, 2000). Estudos conduzidos por Melo et al. (2006) sugeriram que a resistência de $C$. racemosa ao bicho-mineiro poderia estar relacionada ao potencial oxidativo e composição fenólica do tecido foliar. Entretanto, Ramiro et al. (2006) estudaram o papel de compostos fenólicos e das enzimas peroxidase e polifenoloxidase na expressão de resistência em $C$. arabica, $C$. racemosa e em progênies de cruzamentos entre essas espécies, e constataram que nenhuma das classes de substâncias avaliadas desempenharam papel significativo na resistência ao bicho-mineiro do cafeeiro.

Em função de pesquisas que relataram a existência de resistência de $C$. racemosa ao bicho-mineiro, desenvolve-se a hipótese de que essa planta produz substâncias inseticidas, as quais podem afetar esse insetopraga. Desta forma, com vistas a contribuir para o desenvolvimento de novas técnicas para o controle do bicho-mineiro do cafeeiro, o presente trabalho teve como objetivo avaliar o efeito do extrato bruto de $C$. racemosa contra essa praga.

\section{MATERIAL E MÉTODOS}

Mudas de C. racemosa provenientes do banco de germoplasma do Instituto Agronômico de Campinas (SP) foram encaminhadas para o Departamento de Entomologia da Universidade Federal de Lavras, onde foram expostas ao ataque do bicho-mineiro por 15 dias. Posteriormente, folhas frescas $(157,87 \mathrm{~g})$ foram retiradas dessas mudas e levadas para o Laboratório de Produtos Naturais do Departamento de Química da Universidade Federal de Lavras, onde foram picadas e maceradas em metanol por 48 horas para a obtenção do extrato. Em seguida, filtrou-se a mistura resultante em algodão hidrófilo e se adicionou mais metanol ao resíduo. Este procedimento foi repetido mais cinco vezes, até que o sobrenadante apresentasse coloração bem clara. As fases líquidas foram combinadas e concentradas até a secura em evaporador rotatório e liofilizadora, resultando em um resíduo verde escuro e pastoso (extrato), com massa de 13,0828 g, o que correspondeu a um rendimento de $8,3 \%$ na extração.

Os adultos de L. coffeella utilizados nos experimentos foram obtidos de criação mantida em laboratório de acordo com a metodologia proposta por Reis Júnior et al. (2000).

$\mathrm{O}$ teste de oviposição com chance de escolha foi realizado em condições de casa-de-vegetação, onde mudas de cafeeiro Coffea arabica L. cv. Catuaí, com seis meses de idade, tiveram as folhas da base retiradas de modo que restassem apenas quatro folhas por planta. Posteriormente, as folhas foram limpas com algodão umedecido em água destilada para a eliminação de possíveis ovos do bicho-mineiro. Dissolveu-se o extrato em solução aquosa de Tween 80 a $1 \%(\mathrm{~g} / \mathrm{mL})$ até as concentrações de $0,9 \%$ e $1,9 \%(\mathrm{~g} / \mathrm{mL})$, determinadas por meio de ensaios prévios. As soluções resultantes foram aplicadas por meio de pulverizador manual com volume médio de 5,0 $\mathrm{mL}$ por planta. Além das soluções dos extratos, empregou-se água e solução aquosa de Tween 80 a $1 \%(\mathrm{~g} / \mathrm{mL})$ como testemunhas negativas. Cada bloco foi constituído por uma gaiola de madeira $(40 \mathrm{~cm} \mathrm{x} 50 \mathrm{~cm}$ x 41,5 cm) recoberta com organza, na qual foram colocadas as plantas tratadas e vinte casais de adultos do bichomineiro, provenientes da criação de laboratório, com idade variando de um a três dias. As avaliações foram realizadas 24, 48 e 72 horas após a liberação dos adultos pela contagem de ovos nas folhas. O experimento foi conduzido em delineamento, em blocos casualizados, com parcelas subdivididas no tempo e cinco repetições, em que cada planta foi considerada uma parcela experimental. Também foi calculado o Índice de Preferência para Oviposição (IPO) por meio da seguinte equação: IPO = $[(\mathrm{A}-\mathrm{B}) /(\mathrm{A}+\mathrm{B})] \mathrm{x} 100$, sendo $\mathrm{A}$ o número de ovos no tratamento com extrato e $\mathrm{B}$ o número de ovos na testemunha (água). Em geral, esse índice pode variar de +100 (muito estimulante) a -100 (total deterrência ou inibição de oviposição), passando pelo valor 0 (neutro) (Fenemore, 1980).

O efeito ovicida do extrato de $C$. racemosa também foi observado em condições de casa-de-vegetação. Assim, mudas de cafeeiro $C$. arabica cv. Catuaí, com seis meses de idade e com quatro folhas por planta, foram limpas com algodão umedecido em água destilada e acondicionadas em gaiolas ( $40 \mathrm{~cm} \mathrm{x} 120 \mathrm{~cm}$ x $40 \mathrm{~cm}$ ) recobertas com organza. Em cada gaiola, foram colocadas dez mudas de cafeeiro e, em seguida, vinte casais de adultos do bicho-mineiro, obtidos da criação de laboratório, com idade variando de 
um a três dias. Os casais foram colocados nas gaiolas no final da tarde (16:00h), sendo avaliado o número de ovos colocados na manhã do dia seguinte $(8: 00 \mathrm{~h})$. Foram mantidos cinco ovos em média por folha, totalizando aproximadamente vinte ovos por planta. Os demais ovos foram descartados, assim como os adultos do inseto. Os tratamentos empregados foram solução aquosa de Tween 80 a $1 \%$ e água (testemunhas negativas), óleo de neem a $3 \%$ (testemunha positiva) e o extrato de $C$. racemosa a $1,9 \%$. As mudas receberam os tratamentos via pulverização, com volume médio de $5,0 \mathrm{~mL}$ por planta, utilizando-se pulverizador manual. Em seguida, as mudas foram mantidas em gaiolas a fim de se evitarem novas posturas do bicho-mineiro. Sete dias após a pulverização, as folhas foram destacadas e realizou-se a avaliação pela contagem de ovos viáveis e inviáveis com o uso de um microscópio estereoscópico (40x). O experimento foi conduzido em delineamento inteiramente casualizado, com 5 repetições por tratamento, sendo 1 planta considerada como parcela experimental.

Os ovos inviáveis foram submetidos à análise por microscopia eletrônica de varredura (MEV) a fim de se observarem possíveis alterações morfológicas. Para tanto, utilizou-se o protocolo padrão para amostras biológicas de acordo com Alves (2004).

Para avaliar o efeito do extrato sobre parâmetros biológicos relativos à fase adulta de L. coffeella, montouse um experimento de forma semelhante ao teste ovicida em casa-de-vegetação. Utilizaram-se água e solução aquosa de Tween 80 a 1\% como testemunhas negativas, óleo de neem $1,5 \%$ (concentração subletal) como testemunha positiva e extrato de $C$. racemosa a $1,9 \%$. O delineamento experimental foi inteiramente casualizado, com cinco repetições por tratamento e cada parcela correspondeu a uma muda contendo em média vinte ovos.

Quinze dias após a pulverização dos tratamentos nas folhas contendo os ovos, as folhas com minas novas foram destacadas e tiveram seus pecíolos fixados em placas de isopor, que foram colocadas em placas de Petri com o fundo coberto com algodão embebido em solução de benziladenina na concentração de $10^{-6} \mathrm{M}$, conforme metodologia de Reis Júnior et al. (2000). As placas foram acondicionadas em câmara climática mantida nas seguintes condições: $25 \pm 1^{\circ} \mathrm{C}$, UR $70 \pm 10 \%$ e fotofase de $14 \mathrm{~h}$. As pupas formadas foram coletadas e individualizadas, em tubos de vidro $(2 \mathrm{~cm}$ de diâmetro $\mathrm{x}$ $8 \mathrm{~cm}$ de altura), até a emergência dos adultos, para a determinação da porcentagem de emergência (adultos emergidos x 100/número de pupas) e da razão sexual (número de fêmeas/número total de adultos). Para a avaliação da capacidade de oviposição dos adultos recém-emergidos, duas folhas de cafeeiro foram fixadas pelos pecíolos em pedaço de isopor, que foi mantido em placa de Petri com algodão embebido em solução de benziladenina na concentração de $10^{-6} \mathrm{M}$, que foi colocada no interior de uma gaiola de PVC $(15 \mathrm{~cm}$ de altura x $20 \mathrm{~cm}$ de diâmetro), na qual também foi liberado um casal de bichomineiro. Após 48 h, contaram-se os ovos colocados em cada folha.

Os dados coletados em todos os experimentos foram submetidos à análise de variância e se compararam as médias dos tratamentos pelo teste de Scott \& Knott (1974) a 5\% de significância.

\section{RESULTADOS E DISCUSSÃO}

Observou-se redução no número de ovos depositados pelas fêmeas de $L$. coffeella em mudas tratadas com o extrato de $C$. racemosa, em ambas as concentrações avaliadas, após 24, 48 e 72 horas da aplicação dos tratamentos (Tabela 1). O efeito inibidor de oviposição de insetos por metabólitos secundários de plantas é bem conhecido na literatura (Ono et al., 2004; Singh \& Singh, 2007); entretanto, não existem relatos referentes a atividade deterrente de oviposição de C. racemosa para o bicho-mineiro. Contudo, foi verificado que outras espécies de plantas pertencentes à família Rutaceae são capazes de afetar a oviposição de vários lepidópteros-praga. Nesse contexto, foi constatado que o óleo essencial de Chloroxylon swietenia DC. (Rutaceae) reduziu a oviposição de Spodoptera litura (F.) (Lepidoptera: Noctuidae) (Kiran et al., 2006).

No mesmo sentido, Ono et al. (2004) observaram que o extrato metanólico de Orixa japonica Thunb. (Rutaceae) apresentou efeito deterrente de oviposição para Papilio xuthus L. (Lepidoptera: Papilionidae), e levantaram a hipótese de que isso possa ter ocorrido devido ao fato de as substâncias presentes no extrato atuarem como alomônios nos receptores tarsais dos insetos. Também outros autores, como Feeny et al. (1983), afirmaram que a não-preferência para oviposição de insetos em determinado substrato pode ser atribuída ao fato das fêmeas de lepidópteros possuírem sensilas tarsais, as quais percebem a informação fitoquímica quando pousam nas superfícies das folhas, sendo esse um fator determinante para que o inseto aceite ou rejeite ovipositar em determinada planta. Dessa forma, a não-preferência para a oviposição de L. coffeella em mudas de café tratadas com o extrato de C. racemosa pode estar relacionada ao efeito dos metabólitos secundários de C. racemosa sobre os receptores tarsais do bicho-mineiro. 


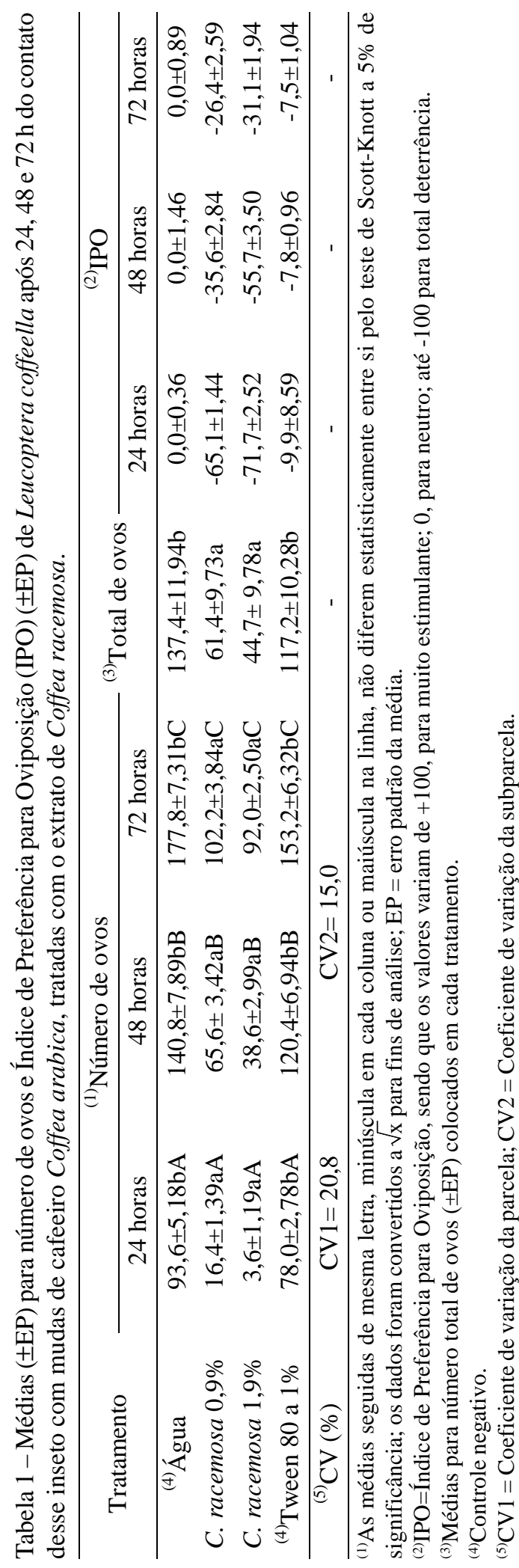


Com relação ao Índice de Preferência para Oviposição (IPO) (Tabela 1), o extrato de C. racemosa apresentou efeito inibidor de oviposição, sendo que tal efeito aumentou com a concentração do extrato e diminuiu com o tempo decorrido após a pulverização. $\mathrm{O}$ fato da oviposição de $L$. coffeella ter sido reduzida com o aumento da concentração do extrato é análogo ao observado por Torres et al. (2006) em trabalho com Plutella xylostella L. (Lepidoptera: Plutellidae). A redução na atividade do extrato de C. racemosa com o decorrer do tempo, constatado no presente trabalho, possivelmente ocorreu devido à baixa estabilidade por parte das substâncias ativas presentes no referido extrato nas condições de realização do experimento. Outros materiais de origem vegetal, como, por exemplo, o óleo essencial de Cymbopogon citratus (D.C.) Stapf. (Poaceae) sofre degradação em função da temperatura, o que provoca alterações em suas propriedades biológicas (Guimarães et al., 2008).

Referente ao teste ovicida, foi observado que o extrato de $C$. racemosa causou redução significativa na percentagem de eclosão das lagartas de L. coffeella (Tabela 2). Apesar da escassez de estudos referentes ao efeito de extratos de plantas sobre a sobrevivência de lepidópteros na fase embrionária, os resultados encontrados no presente trabalho estão em consonância com aqueles obtidos por Magalhães et al. (2004). Tais autores, ao estudarem a interação entre $L$. coffeella e genótipos híbridos de C. arabica x C. racemosa, constataram redução na percentagem de eclosão do bicho-mineiro em ovos colocados nas folhas de C. racemosa e de alguns dos híbridos testados, o que os levou a inferir que a antibiose seria o principal mecanismo responsável pela resistência de C. racemosa ao inseto. Tal hipótese é suportada pelos resultados observados no presente trabalho, haja vista que o efeito letal do extrato de C. racemosa sobre ovos do bicho-mineiro é indicativo da produção de metabólitos secundários por essa planta.

A partir de análises por microscopia eletrônica de varredura, foi possível constatar anomalias nas superfícies externas dos ovos inviáveis tratados com óleo de neem e com o extrato de $C$. racemosa (Figura 1). Apesar de o mecanismo de ação ovicida do extrato de C. racemosa sobre $L$. coffeella ser incerto até o presente momento, é sabido que alterações em quaisquer das camadas do córion podem afetar a sua permeabilidade (Chapman, 1998). Assim, possivelmente as referidas anomalias, constatadas neste trabalho, possam ter contribuído para a entrada de substâncias que afetaram o desenvolvimento embrionário do inseto e, consequentemente, a viabilidade dos ovos.

Os adultos do bicho-mineiro provenientes de ovos tratados com o extrato não apresentaram alterações na percentagem de emergência, razão sexual e fecundidade (Tabela 3). É possível que isso tenha ocorrido devido ao hábito minador desse inseto e ao baixo efeito translamilar do extrato, uma vez que, ao eclodir, a lagarta penetra no mesofilo foliar, não entrando mais em contato com a superfície da folha que recebeu o tratamento, exceto no momento de pupação. As substâncias ativas presentes no extrato podem não apresentar capacidade de translocação para o mesofilo e, em decorrência disso, não afetarem as lagartas. Além disso, deve-se também considerar o efeito residual do extrato, já que, no momento da pupação, em que as lagartas novamente entram em contato com a superfície da folha que recebeu o tratamento, os compostos ativos presentes no extrato podem estar em nível residual inferior ao necessário para provocar alterações no desenvolvimento do bichomineiro.

A falta de efeito residual por parte de extratos vegetais encontra sustentação no trabalho desenvolvido por Souza \& Vendramim (2000), que constataram

Tabela 2 - Médias ( \pm EP) para a porcentagem de eclosão de lagartas de Leucoptera coffeella após o tratamento dos ovos com o extrato de Coffea racemosa.

\begin{tabular}{lc}
\hline Tratamento & ${ }^{(1)}$ Porcentagem de eclosão de lagartas \\
\hline Óleo de neem 3\% (v/v) (controle positivo) & $15,2 \pm 3,41 \mathrm{a}$ \\
C. racemosa a $1,9 \%$ & $34,6 \pm 6,02 \mathrm{~b}$ \\
Água (controle negativo) & $94,3 \pm 2,71 \mathrm{c}$ \\
Tween 80 a $1 \%$ (controle negativo) & $94,5 \pm 2,55 \mathrm{c}$ \\
\hline CV $(\%)$ & 15,6 \\
\hline
\end{tabular}

${ }^{(1)}$ As médias seguidas de mesma letra não diferem estatisticamente entre si pelo teste de Scott-Knott a 5\% de significância. 
mortalidade dos ovos de Bemisia tabaci (Gennadius) (Hemiptera: Aleyrodidae) tratados com os extratos de Melia azedarach L. (Meliaceae) e de Trichilia pallida Swartz (Meliaceae). Entretanto, os extratos aplicados sobre os ovos pouco afetaram a sobrevivência ninfal, sendo que os autores atribuíram tais resultados ao baixo poder residual do extrato.

A informações referentes à ação dos metabólitos secundários de $C$. racemosa na oviposição e viabilidade dos ovos de L. coffeella, encontradas no presente trabalho, são importantes para o desenvolvimento de métodos alternativos para o controle desse inseto, principalmente, em cultivos orgânicos de cafeeiro. Trabalhos posteriores deverão ser realizados com os objetivos de isolar e identificar a(s) substância(s) responsável(is) pela atividade observada contra o bichomineiro e avaliar o desempenho do extrato de C. racemosa no controle do bicho-mineiro, em condições de campo.
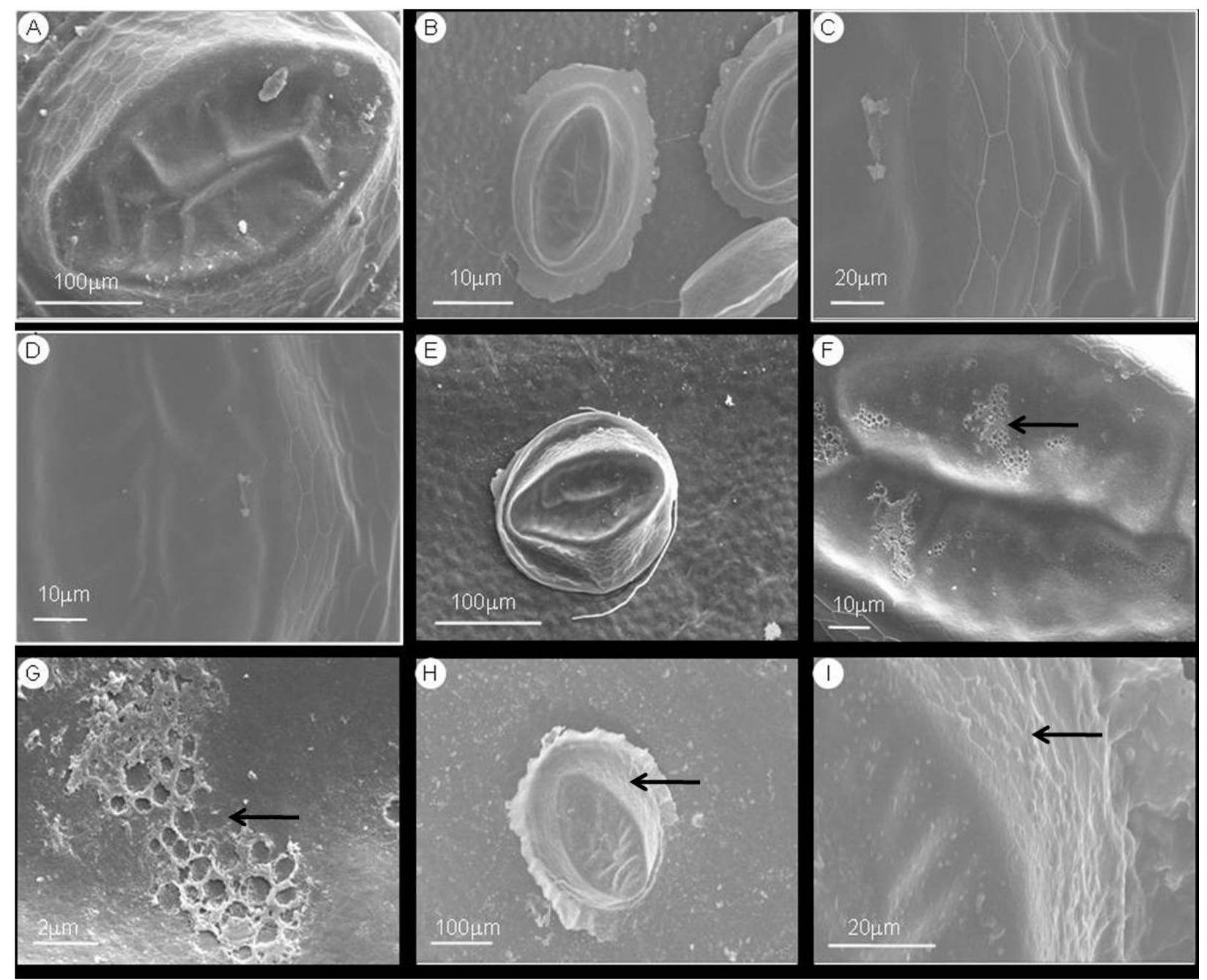

Figura 1 - Análise ultraestrutural de ovos inviáveis de Leucoptera coffeella por microscopia eletrônica de varredura. $\mathrm{A}$ e $\mathrm{B}=$ ovos tratados com água; $\mathrm{C}$ e $\mathrm{D}=$ tratados com solução aquosa de Tween 80 a $1 \%$; E, F e $\mathrm{G}=$ tratados com o extrato de Coffea racemosa a 1,9\%, apresentando alterações morfológicas na superfície externa, indicadas por setas; H e I = ovos tratados com óleo de neem a 3,0\%, apresentando alterações morfológicas na superfície externa (indicadas por setas). 
Tabela 3 - Médias ( \pm EP) para porcentagem de emergência, razão sexual e oviposição de adultos provenientes de ovos de Leucoptera coffeella expostos ao extrato de Coffea racemosa.

\begin{tabular}{lccc}
\hline Tratamento & Emergência $(\%)^{* *}$ & Razão sexual** & Número de ovos/casal* \\
\hline${ }^{(1)}$ Óleo de neem a 1,5\% & $77,5 \pm 4,48$ & $0,4 \pm 0,06$ & $19,8 \pm 4,96 \mathrm{a}$ \\
C. racemosa a 0,9\% & $63,6 \pm 2,71$ & $0,5 \pm 0,03$ & $40,7 \pm 10,72 \mathrm{~b}$ \\
${ }^{(2)}$ Tween 80 a 1\% & $77,0 \pm 2,69$ & $0,5 \pm 0,01$ & $37,9 \pm 8,91 \mathrm{~b}$ \\
${ }^{(2)}$ Água & $81,6 \pm 2,27$ & $0,5 \pm 0,01$ & $36,0 \pm 6,22 \mathrm{~b}$ \\
\hline CV $(\%)$ & 19,3 & 38,2 & 15,8 \\
\hline
\end{tabular}

*As médias seguidas de mesma letra, em cada coluna, não diferem estatisticamente entre si pelo teste de Scott-Knott a 5\% de significância.

**Não significativo ( $\mathrm{p}>0,05)$.

${ }^{(1)}$ Controle positivo; ${ }^{(2)}$ Controle negativo.

\section{CONCLUSÕES}

Substâncias presentes no extrato de C. racemosa apresentam inibidores de oviposição para L. coffeella.

A aplicação do extrato de $C$. racemosa em ovos do bicho-mineiro, além de provocar anomalias nos ovos, reduz a taxa de eclosão das lagartas.

Os adultos do bicho-mineiro oriundos de ovos tratados com o extrato de C. racemosa não apresentam alterações na percentagem de emergência, razão sexual e fecundidade.

\section{AGRADECIMENTOS}

Ao Dr. Guerreiro Oliveira Filho do Instituto Agronômico de Campinas pela doação das mudas de C. racemosa. Ao suporte financeiro e concessão de bolsas pela FAPEMIG, CNPq e CAPES.

\section{REFERÊNCIAS BIBLIOGRÁFICAS}

ALMEIDA, S.A.; ALMEIDA, F.A.C.; SANTOS, N.R.; MEDEIROS, S.S.A.; ALVES, H.S. Controle do caruncho Callosobruchus maculatus (Fabr., 1775) (Coleoptera: Bruchidae) utilizando extratos de Piper nigrum L. (Piperaceae) pelo método de vapor. Ciência e Agrotecnologia, Lavras, v.30, n.4, p.793-797, jul./ago. 2006.

\section{ALVES, E. Introdução à microscopia eletrônica de varredura. Lavras: FAEPE, 2004. 43p.}

CHAPMAN, R.F. The insects: structure and function. Cambridge: Cambridge University, 1998. 770p.

FEENY, P.; ROSENBERRY, L.; CARTER, M. Herbivorous Insects. In: AHMAD, S. Chemical aspects of oviposition behavior in butterflies. New York: Academic, 1983. p.27-76.

FENEMORE, P.G. Oviposition of potato tuber moth, Phthorimaea operculella Zell. (Lepidoptera: Gelechiidae): identification of host plant factors influencing oviposition response. New Zealand Journal of Zoology, Wellington, v.7, p.435-439, 1980.

GONÇALVES-GERVÁSIO, R.C.R.; VENDRAMIM, J.D. Bioatividade do extrato aquoso de sementes de nim sobre Tuta absoluta (Meyrick, 1917) (Lepidoptera: Gelechiidae) em três formas de aplicação. Ciência e Agrotecnologia, Lavras, v.31, n.1, p.28-34, jan./fev. 2007.

GUERREIRO-FILHO, O.; MAZZAFERA, P. Caffeine does not protect coffee against the leaf miner Perileucoptera coffeella. Journal of Chemical Ecology, New York, v.26, n.6, p.1447-1464, June 2000.

GUIMARÃES, L.G.L.; CARDOSO, M.G.; ZACARONI, L.M.; LIMA, R.K.; PIMENTEL, F.A.; MORAIS, A.R. Influência da luz e da temperatura sobre a oxidação do óleo essencial de capim-limão (Cymbopogon citratus (D.C.) Stapf). Química Nova, São Paulo, v.31, n.6, p.14761480, ago. 2008.

KIRAN, S.R.; REDDY, A.S.; DEVI, P.S.; REDDY, K.J. Insecticidal, antifeedant and oviposition deterrent effects of the essential oil and individual compounds from leaves of Chloroxylon swietenia DC. Pest Management Science, London, v.62, n.1, p.1116-1121, 2006. 
LIMA, R.K.; CARDOSO. M.dasG.; SANTOS, C.D.dos; MORAES, J.C.; NÉRI, D.K.P.; NASCIMENTO, E.A.do. Caracterização química do óleo essencial de folhas de goiabeira (Psidium guajava L.) e seus efeitos no comportamento da lagarta-do-cartucho do milho Spodoptera frugiperda (J. E. Smith, 1797) (Lepidoptera: Noctuidae). Ciência e Agrotecnologia, Lavras, v.33, n. E. Especial, p. 1777-1781, 2009.

MAGALHÃES, S.T.V.; LIMA, E.R.; GUEDES, R.N.C.; PEREIRA, A.A.; CUNHA, F.F. Interação entre bichomineiro e híbridos de Coffea arabica x Coffea racemosa, em condições controladas. Bioscience Journal, Uberlândia, v.20, n.1, p.9-14, jan./fev. 2004.

MELO, G.A.; SHIMIZU, M.M.; MAZZAFERA, P. Polyphenoloxidase activity in coffee leaves and its role in resistance against the coffee leaf miner and coffee leaf rust. Phytochemistry, Oxford, v.67, n.3, p.277-285, Feb. 2006.

\section{MENDES, A.N.G. Biotecnologia $\mathbf{x}$ métodos}

convencionais de melhoramento: informativo Garcafé, 1999. Disponível em: <http://Www.coffeebreak.com.bry. Acesso em: 22 jul. 2008.

MENDONÇA, J.M.A.; CARVALHO, G.A.; GUIMARÃES, R.J.; REIS, P.R.; ROCHA, L.C.D. Produtos naturais e sintéticos no controle de Leucoptera coffeella (GuérinMèneville \& Perrottet, 1842) (Lepidoptera: Lyonetiidae) e seus efeitos sobre a predação por vespas. Ciência e Agrotecnologia, Lavras, v.30, n.5, p.892-899, set./out. 2006.

OLIVEIRA, M.S.S.; ROEL, A.R.; ARRUDA, E.J.; MARQUES, A.S. Eficiência de produtos vegetais no controle da lagarta-do-cartucho-do-milho Spodoptera frugiperda (J.E. Smith, 1797) (Lepidoptera: Noctuidae). Ciência e Agrotecnologia, Lavras, v.31, n.2, p.326- 331, mar./abr. 2007.

ONO, H.; KUWAHARA, Y.; NISHIDA, R.

Hydroxybenzoic acid derivatives in a nonhost rutaceous plant, Orixa japonica, deter both oviposition and larval feeding in a rutaceae-feeding swallowtail butterfly, Papilio xuthus L. Journal of Chemical Ecology, New York, v.30, p.287-301, Feb. 2004.

PEREIRA, A.C.R.L.; OLIVEIRA, J.V.; GONDIM JUNIOR, M.G.C.; CAMARA, C.A.G. Atividade inseticida de óleos essenciais e fixos sobre Callosobruchus maculatus (FABR., 1775) (Coleoptera: Bruchidae) em grãos de caupi [Vigna unguiculata (L.) WALP.]. Ciência e Agrotecnologia, Lavras, v.32, n.3, p.717-724, maio/jun. 2008.

RAMIRO, D.A.; GUERREIRO, O.; MAZZAFERA, P. Phenol contents, oxidase activities, and the resistance of coffee to the leaf miner Leucoptera coffeella. Journal of Chemical Ecology, New York, v.32, n.9, p.1977-1988, Sept. 2006.

RAMIRO, D.A.; GUERREIRO-FILHO, O.; QUEIROZVOLTAN, R.B.; MATTHIESEN, S.C. Caracterização anatômica de folhas de cafeeiros resistentes e suscetíveis ao bicho-mineiro. Bragantia, Campinas, v.63, n.3, p.363-372, dez. 2004.

REIS JUNIOR, R.; LIMA, E.R.; VILELA, E.F.; BARROS, R.S. Method for maintenance of coffee leaves in vitro for mass rearing of Leucoptera coffeella (Guérin-Mèneville) (Lepidoptera:

Lyonetiidae). Anais da Sociedade Entomológica do Brasil, Londrina, v.29, n.3, p.849-854, May/June 2000.

ROSSI, G.D.; SANTOS, C.D.dos; CARDOSO, M.dasG.; CORRÊA, A.D.; ABREU, C.M.P.de; PAIVA, L.V. Inibição da tripsina de bicho-mineiro do cafeeiro por um fator não-protéico presente em extratos de folhas de mamona. Ciência e Agrotecnologia, Lavras, v.34, n.2, p.361-366, mar./abr., 2010.

SANTIAGO, G.P.; PÁDUA,L.E.M.; SILVA, P.R.R.; CARVALHO,E.M.S.; MAIA, C.B. Efeitos de extratos de plantas na biologia de Spodoptera frugiperda (J. E. Smith, 1797) (Lepidoptera: Noctuidae) mantida em dieta artificial. Ciência e Agrotecnologia, Lavras, v.32, n.3, p.792-796, maio/jun. 2008.

SCOTT, A.J.; KNOTT, M. A cluster analysis method for grouping means in the analysis of variance.

Biometrics, Raleigh, v.30, n.3, p.507-512, Sept. 1974.

SILVA, P.A.; OLIVEIRA, D.F.; PRADO, N.R.T.; CARVALHO, D.A.; CARVALHO, G.A. Evaluation of the antifungal activity by plant extracts against Colletotrichum gloeosporioides Penz. Ciência e Agrotecnologia, Lavras, v.32, n.2, p. 420-428, mar./abr. 2008. 
SINGH, R.; SINGH, R. Insecticidal potential of Pongamia pinnata seed fractions of methanol extract against Earias vittella (Lepidoptera: Noctuidae). Entomologia Generalis, Stuttgart, v.30, n.1, p.51-62, Jan. 2007.

SOUZA, A.P.; VENDRAMIM, J.D. Atividade ovicida de extratos aquosos de meliáceas sobre a mosca branca Bemisia tabaci (Gennadius) biótipo B em tomateiro.
Scientia Agricola, Piracicaba, v.57, n.3, p.403-406, jul./ set. 2000.

TORRES, A.L.; BOIÇA JÚNIOR, A.L.; MEDEIROS, C.A.M.; BARROS, R. Efeito de extratos aquosos de Azadirachta indica, Melia azedarach e Aspidosperma pyrifolium no desenvolvimento e oviposição de Plutella xylostella. Bragantia, Campinas, v.65, n.3, p.447-457, set. 2006. 